\title{
Indication-Specific Approach to Filler Injections
}

\author{
Sabine Zenker* \\ Dermatologist, Dr Zenker Dermatology, Germany
}

Submission: June 1, 2018; Published: June 27, 2018

*Corresponding author: Sabine Zenker, Dermatologist, Dr Zenker Dermatology, Maximilianstraße, Germany, Tel: 0049-89-552769-0; Email: kontakt@ dr-zenker-services.de.

\section{Summary}

Facial aging is a complex process resulting in appearance of wrinkles and folds as well as sagging and volume loss. This article does outline a science-based, indication-specific therapeutic concept for filler injections to the aging ace.

Keywords: Indication specific treatment; Filler; Fill; Ftimulate; Volumize

\section{The Age-Related Three-Dimensional Facial Changes}

Even though facial aging starts at the surface by showing signs of skin aging, the changes go far beyond the skin: it finally involves all other facial structures such as the muscles, retaining ligaments, fat pads and the bony structures. Predominantly and for a youthful and appealing look, the architecture and position of the fat pads is pivotal. But over time, the facial fat pads get redistributed, they do atrophy and get separated [1-6]. Further to this, a remarkable bony resorption takes place and doesn't give the needed structural support [3,6,7]. All this results in deflation, volume loss and sagging in a three-dimensional way $[6,8]$.

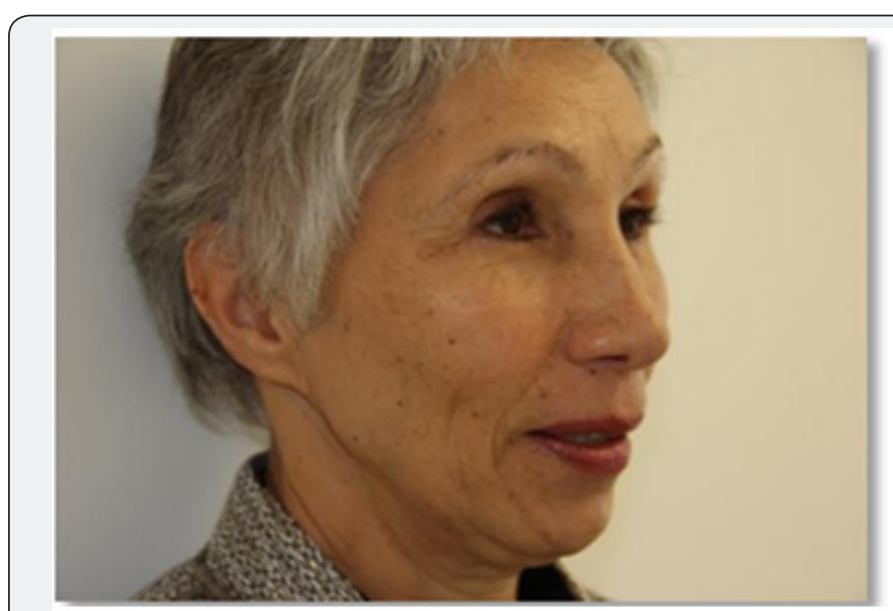

Figure 1: Indication Wrinkles CDr med. Sabine Zenker.

\section{Volume Loss}

Further changes such as the appearance of shades, furrows, volume loss and overall sagging are the next typical indication for facial filler injections to restore facial proportions in order

\section{Typical Indications for Filler Treatments}

Here, very importantly, filler treatments come into play. Any treatment in aesthetic dermatology does require an indicationspecific treatment approach, the individual diagnosis has to be set up in order to decide for the respective treatment plan. Typical indications for filler treatments are:

\section{Wrinkles}

Creases, wrinkles and folds are a typical sign of skin aging and can give facial expressions an unwanted negative touch (Figure 1)

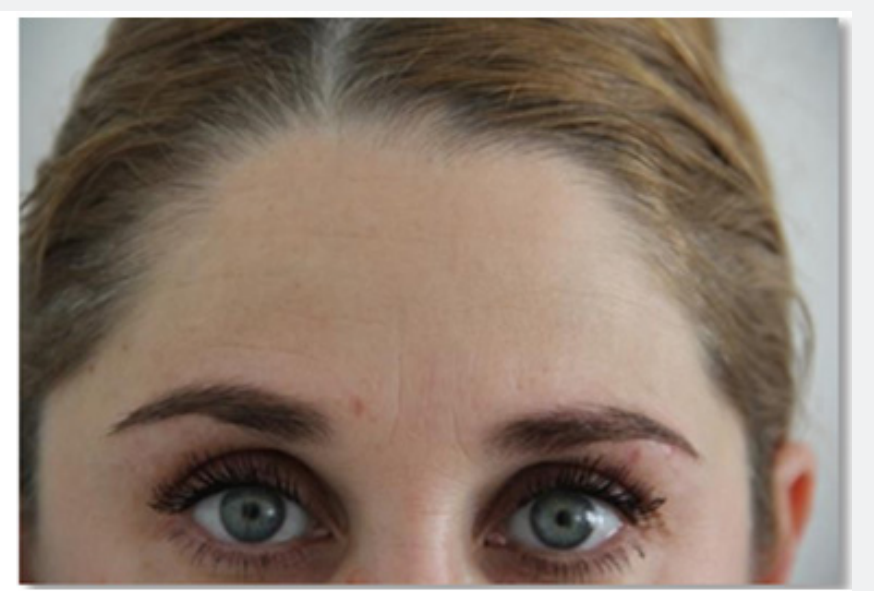

to get back the pleasing facial features one had in the past or to improve aspects such as shape, form and volume of a face; basically, it's about to give back a healthy look with natural fullness and soft and smooth transitions (Figure 2). 


\section{Juniper Online Journal of Dermatology \& Cosmetics}

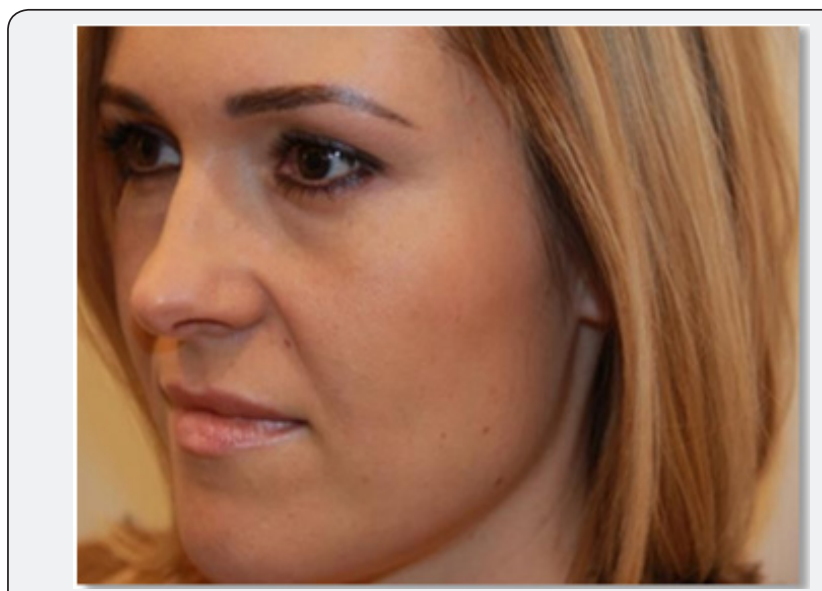

Figure 2: Indication Volume loss @Dr med. Sabine Zenker.

\section{Treatment Concept for Wrinkles by Filler Injections}

Here, the concept offilling wrinkles [directfilling by hyaluronic acid [HA]] and of dermal stimulation by polycaprolactone [PCL] will be discussed.

For direct filling by hyaluronic acid, typical indications on forehead- or perioral lines etc.., the filler is injected intra-dermally in a retrograde fashion ["blanching"] by serial-puncture- or linear- threading, using a sharp needle [30G 1/2"] [9]. The author does mix the respective hyaluronic acid with local anesthetics in a ratio up to $30 \%$ [off-label-use!] to basically achieve an optimal integration of the filler material in the superficial dermis. The correction should never be done over the clinical endpoint. To control filler placement, author often uses injection systems as this increases the accuracy of filler placement and its dose which reduces side effects such as pain and bruising to improve the overall aesthetic outcome in especially such very superficial injections [10]. The result of this direct filling technique with hyaluronic acid lasts -depending on material used and individual conditions- for some months (Figure 3-6).

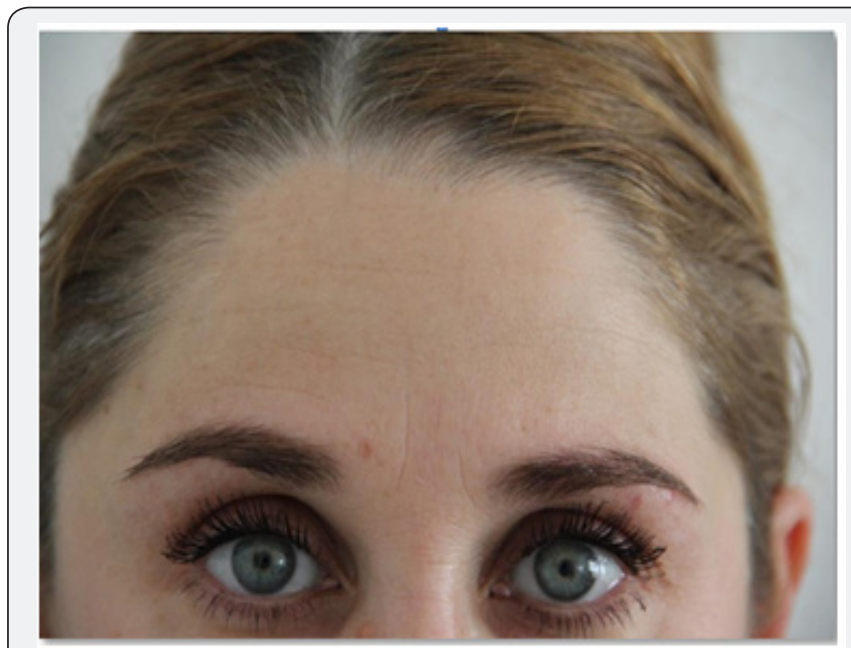

Figure 3: Indication wrinkles: Before direct filling with Hyaluronic Acid (Perfectha ${ }^{\circ}$ Fine Lines), CDr med. Sabine Zenker.

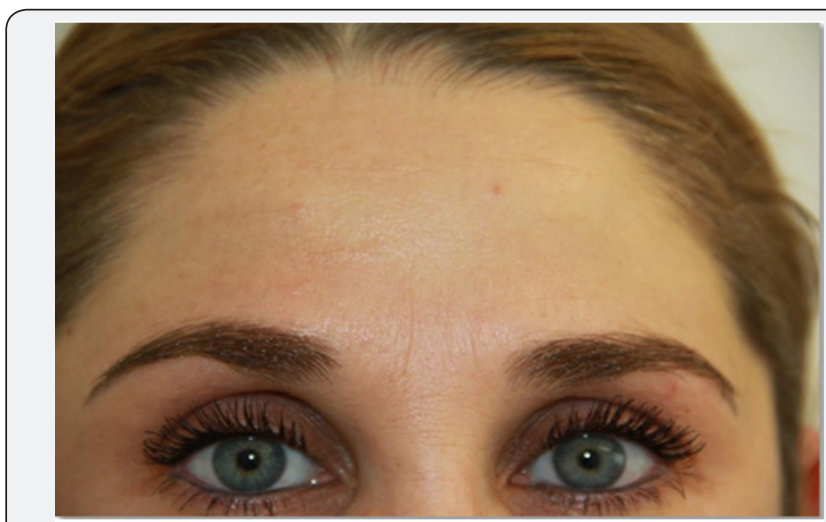

Figure 4: Indication wrinkles: After direct filling with Hyaluronic Acid (Perfectha® Fine Lines), CDr med. Sabine Zenker.

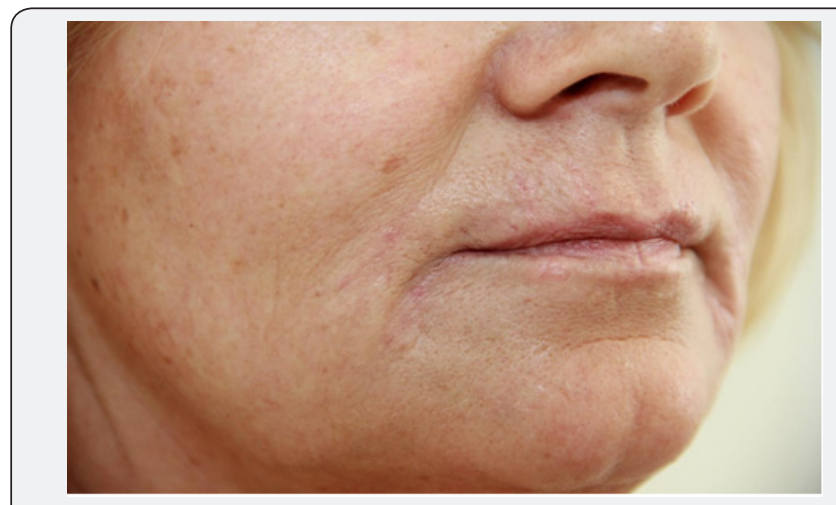

Figure 5: Indication wrinkles: Before direct filling with Hyaluronic Acid (Liquid Implant ${ }^{\circledR}$ Labium), CDr med. Sabine Zenker.

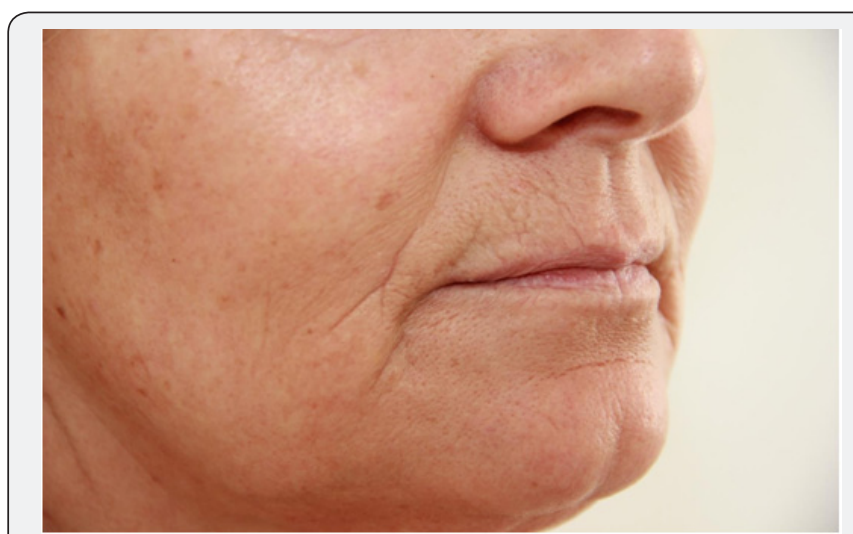

Figure 6: Indication wrinkles: After direct filling with Hyaluronic Acid (Liquidimplant Labium®), CDr med. Sabine Zenker.

The stimulation technique by filler using polycaprolactone [PCL] is especially suited if an immediate filling is desired. Additionally, the effect of collagen stimulation starts appr. 3 months after injection. Polycaprolactone is a biodegradable filler material consisting of microparticles of PCL suspended in a gel carrier [carboxy-methyl-cellulose [CMC] with both, volumizing and stimulating capacities $[11,12]$. This filler has to be placed using a $25 \mathrm{G} 1 \frac{1}{2} 2$ " blunt tipped cannula in a subscision-wise way: PCL is fanned sub-dermally in a fan pattern to cover the whole 
area to be treated in a retrograde fashion; the point of insertion is chosen in a $90^{\circ}$ angle and in the middle of each respective fold. The approximate amount of filler to be injected is 0.1cc (Figure $7,8)$.

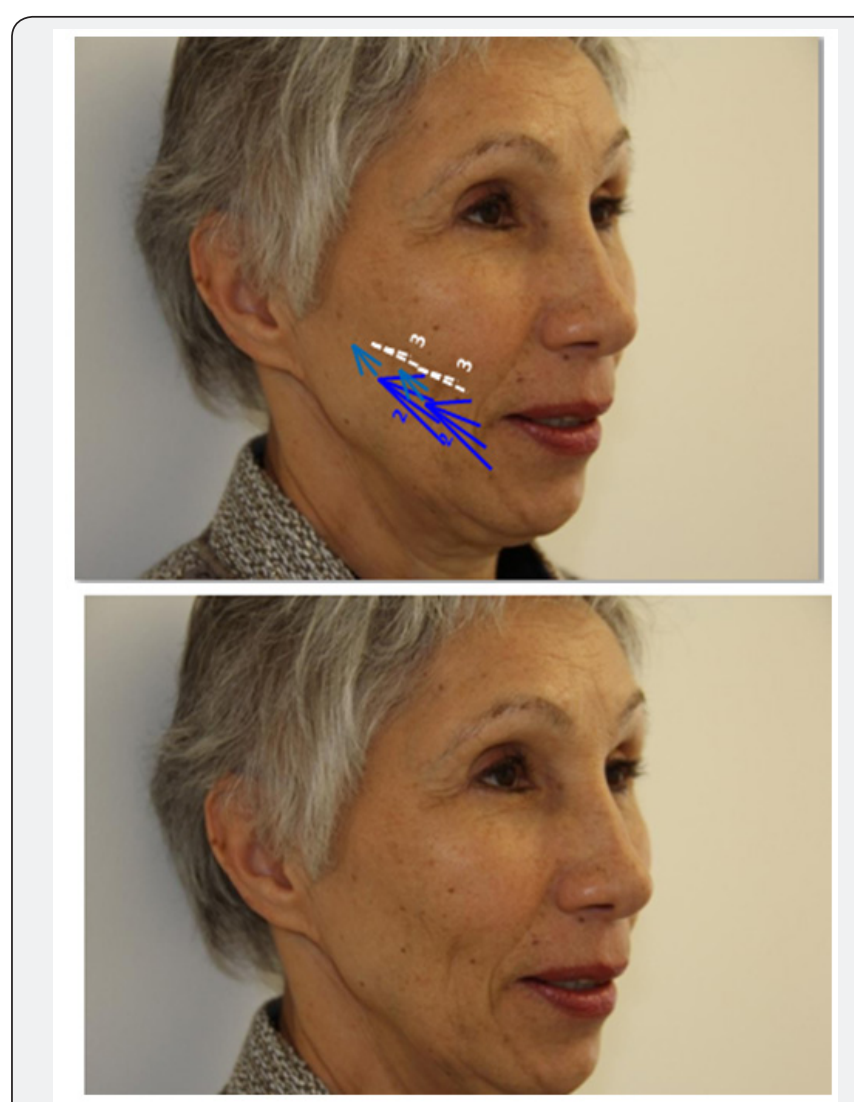

Figure 7: Indication wrinkles: before stimulation by filler treatment with Polycaprolactone (ELLANSĖ $®$ M), $\odot$ Dr med.

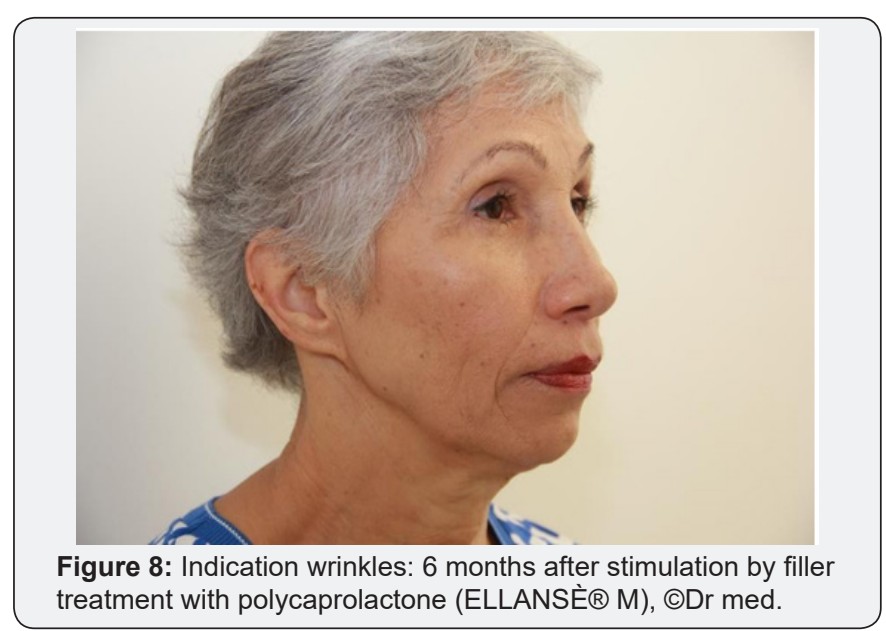

Treatment Concept for Volume Loss by Filler Injections

The treatment of the three-dimensional volume loss will be showcased here by demonstrating techniques for the midface. He tTypical indications here are the sunken-in frontal part of the cheek and the sagged lateral part.
To plan the individual injection strategy, to identify to be treated areas with its entry points as well as the danger zones, facial mapping is pretty use- and helpful (Figure 9).

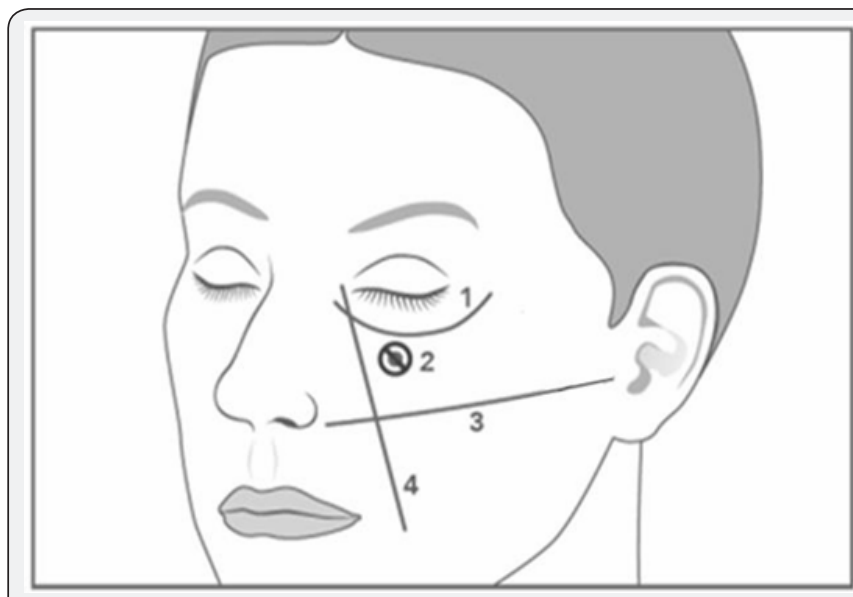

Figure 9: Mapping @Merz Aesthetics

1 = lower orbit, 2 = Foramen infraorbitale, 3 = Alar-Tragus-Line, $4=$ Mediale Canthus Line.

Here, typically highly visco-elastic hyaluronic acid fillers with a good volumizing capacity $[13,14]$, Calcium Hydroxylapatite, CaHA [Radiesse (C)], a calcium particles based filler $[15,16]$ or Polycaprolactone [PCL] are used. The use of blunt tipped cannulas results in a more atraumatic [15], quicker treatment procedure, especially when the filler needs to be placed over "longer distances" [16-22].

The following pictures illustrate typical entry points for this treatment concept, the Cheek-Apex- Entry-Point and the Zygomatic Entry-Point.

The Cheek Apex Entry-Point, entry-point to treat the sunkenin frontal part of the chees, is the point around which the frontal projection of the cheek will be reconstituted (Figure 10).

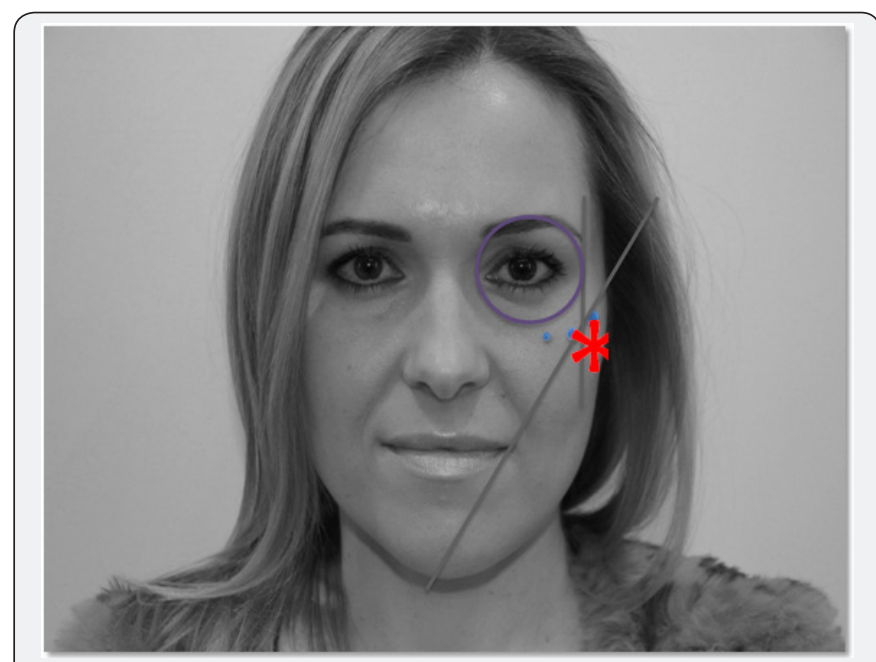

Figure 10: Cheek Apex Entry-Point @Dr med. Sabine Zenker.

The Zygomatic Arch Entry-Point, entry-point to treat the sagged lateral part of the cheeks, is the starting point from which the lateral lifting will be effected (Figure 11). 


\section{Juniper Online Journal of Dermatology \& Cosmetics}

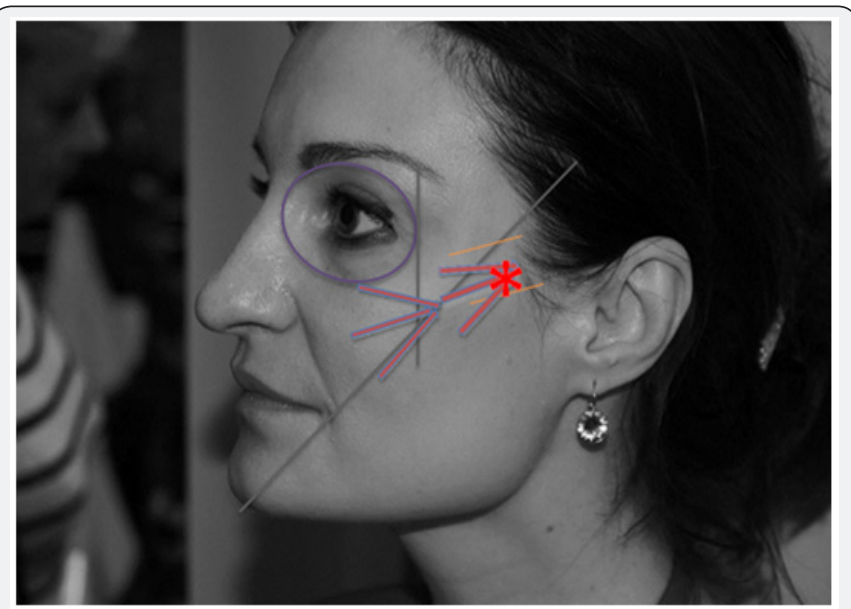

Figure 11: Zygomatic Arch Entry-Point @Dr med. Sabine Zenker.

\section{Sunken-in frontal part cheek}

Starting point is the Cheek Apex Entry-Point. The filler is injected in a bolus technique ["gunshot- wise"], in a retrograde way and placed supraperiostally; according to the clinical needs, more injections medial and eventually lateral of the first entrypoint are performed in a "banana-wise" way. Amount of filler per point is approximately $0.1 \mathrm{cc}$. Augmentation is conducted up to the clinical endpoint.

\section{Sagged lateral part cheek}

Starting point is the Zygomatic Arch Entry-Point. The filler is injected in a fanning technique in retrograde fashion starting supraperiostally and ending up subdermally on the most lateral part of the to be injected area. Amount of filler per point is approximately $0.1-0.2 \mathrm{cc}$. Augmentation is conducted up to the clinical endpoint.

Using these two techniques the frontal projection of the cheeks as well as the lateral lifting can be effected in a customized and individual way.

Here, the following illers are used: hyaluronic acid Perfectha $(C$ Subskin and Calcium Hydroxylapatite [Radiesse $\mathbb{C}$ ] [mixed with Lidocain $1 \%$ in a $20 \%$ ratio]. As equipment, a blunt tip cannula $25 \mathrm{G} / 38 \mathrm{~mm}$ is used [Steriglide $\AA$ ] (Figure 12-16).

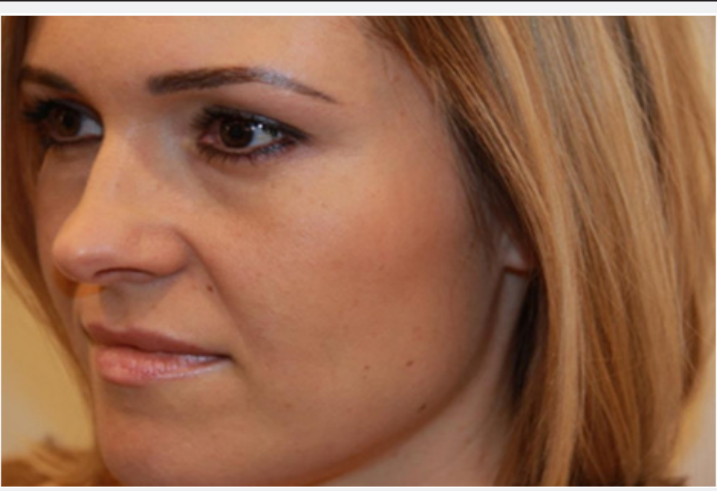

Figure 12: Indication volume loss: before treatment volume loss by fillers with Perfectha@ Subskin@Dr med. Sabine Zenker.

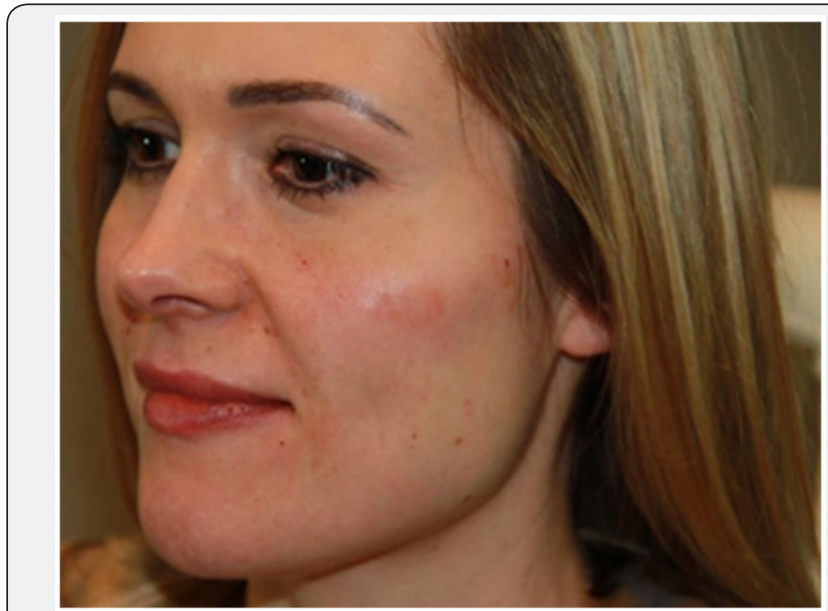

Figure 13: ZIndication volume loss: after treatment volume loss by fillers with Perfectha@ Subskin@Dr med. Sabine Zenker.

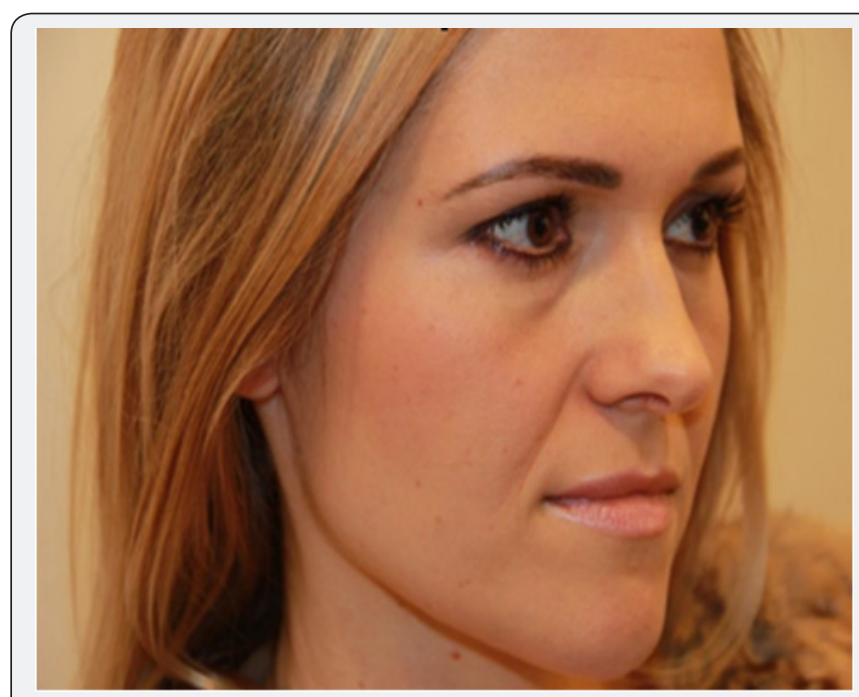

Figure 14: Indication volume loss: before treatment volume loss by fillers with Perfectha@ Subskin@Dr med. Sabine Zenker.

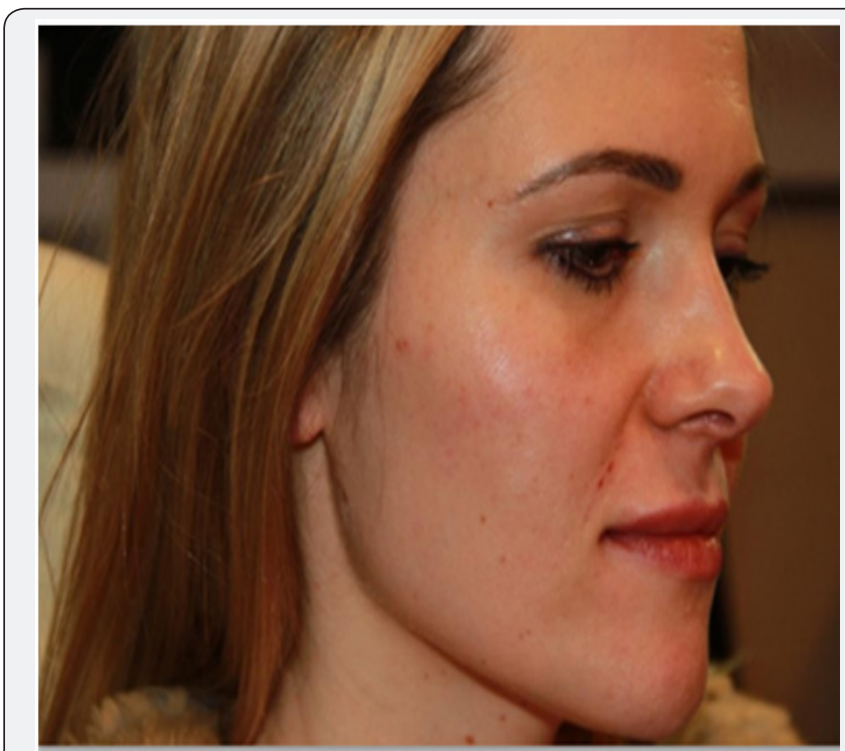

Figure 15: Indication volume loss: After treatment volume loss by fillers with Perfectha@ Subskin@Dr med. Sabine Zenker. 


\section{Juniper Online Journal of Dermatology \& Cosmetics}

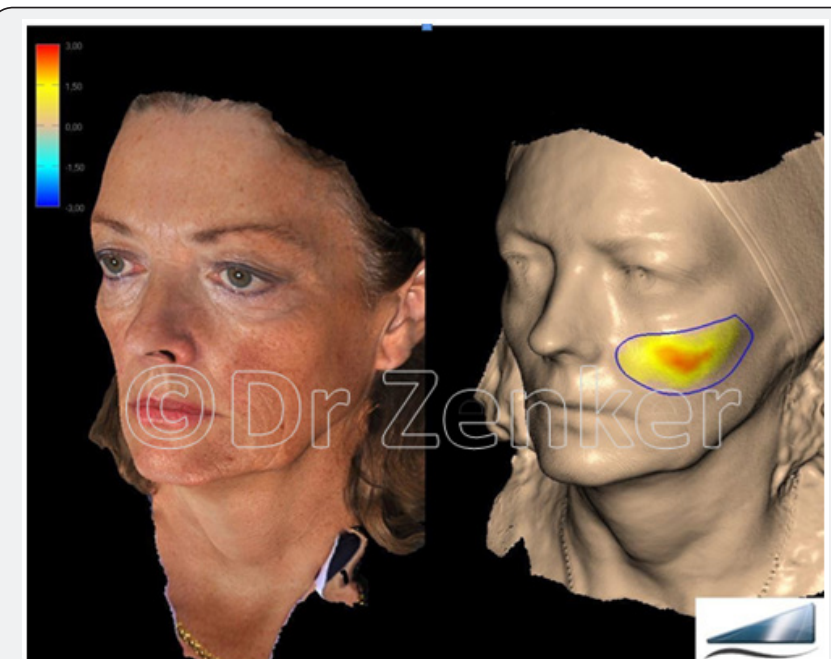

Figure 16: Indication volume loss: Treatment volume loss by fillers with Calcium Hydroxylapatite (Radiesse ${ }^{\circledR}$ ) 3-D-Analyse Quantificare@, @Dr med. Sabine Zenker.

\section{Summary}

Age related facial changes such wrinkles, volume loss and sagging can be easily and individually treated by filler. The indication-specific filler treatment approach helps to identify the respective indications. Thanks to the versatility of degradable fillers, they can serve for all, filling, stimulating as well as volumizing.

\section{References}

1. Murphy MR, Johnson CM, Azizzadeh B, (2006) The aging face consultation. In: Master Techniques in Facial Rejuvenation. Elsevier, p. $1-16$.

2. Coleman SR, Grover R (2006) The anatomy of the aging face: volume loss and changes in 3-dimensional topography. Aesthet Surg J 26(suppl 1): S4-S9.

3. Vleggaar D, Fitzgerald R (2008) Dermatological implications of skeletal aging: a focus on supraperiosteal volumization for perioral rejuvenation. J Drugs Dermatol 7(3): 209-220.

4. Donofrio LM (2000) Fat distribution: a morphologic study of the aging face. Dermatol Surg 26(12): 1107-1112.

5. Zimbler MS, Kokoska MS, Thomas JR. (2001) Anatomy and pathophysiology of facial aging. Facial Plast Surg Clin North Am 9(2): 179-187.

6. Rohrich RJ, Pessa JE (2007) The Fat Compartments of the Face: Anatomy and Clinical Implications for Cosmetic Surgery. Plastic \& Reconstructive Surgery 119(7): 2219-2227.
7. Pessa JE, Chen Y (2002) Cure analysis of the aging orbital aperture. Plast Reconstr Surg 109(2): 751-75 5

8. Mendelson BC, Hartley W, Scott M, McNab A, Granzow JW(2007) Agerlated changes of the orbit and midcheek and the implications for facial rejuvenation. Aesthetic Plast Surg 31(5): 419-423.

9. Monheit G, Coleman KM (2006) Hyaluronic acid fillers. Dermatologic Therapy 19(3): 141-150.

10. Glogau R, Kane MA (2008) Effect of Injection Techniques on the Rate of Local Adverse Events in Patients. Implanted with Nonanimal Hyaluronic Acid Gel Dermal Fillers. Dermatol Surg 34(supply 1): s105109.

11. Nicolau PJ (2013) Neocollagenesis after injection of a polycaprolactone based dermal filler in a rabbit. Eur J Aesth Med Dermatol 3(1): 19-26.

12. Kim JA, Van Abel D (2015) Neocollagenesis in human tissue injected with a polycaprolactone-based dermal filler. J Cosmet Laser Ther 17(2): 99-101.

13. Kablik J, Gary D. Monheit, Liping Y, Chang G, et al. (2009) Comparative Physical Properties of Hyaluronic Acid Dermal Fillers. Dermatol Surg 35(s1): 302-312.

14. Edsman K, Nord LI, Öhrlund P, Lärkner H, Helander KA, et al. (2012) Gel Properties of Hyaluronic Acid Dermal Fillers. Dermatol Surg 38(7pt2): 1170-1179.

15. Sundaram H Voigts B, Beer K, Meland M (2010) Comparison of the rheological properties of viscosity and elasticity in two categories of soft tissue fillers: calcium hydroxylapatite and hyaluronic acid. Dermatol Surg 36(3): 1859-1865.

16. Stocks D, Sundaram H, Michaels J, Durrani MJ, Wortzman MS, et al (2011) Rheological evaluation of the physical properties of hyaluronic acid dermal fillers. J Drugs Dermatol 10(9): 974-980.

17. Radiesse (injectable calcium hydroxylapatite) [prescribing information] (2012) Merz Aesthetics, Inc. In: Franksville WI, Gilbert E (Eds.), J Drugs Dermatol 11(9): 1059-1068.

18. Hexsel D, Soirefmann M, Porto MD, Siega C, Schilling-Souza J, et al (2012) Double-blind, randomized, controlled clinical trial to compare safety and efficacy of a metallic cannula with that of a standard needle for soft tissue augmentation of the nasolabial folds. Dermatol Surg 38(2): 207-214.

19. Fulton J, Caperton C, Weinkle S, Dewandre L (2012) Filler injections with the blunt-tip microcannula. Drugs Dermatol 11(9): 1098-1103.

20. Dewandre L et al (2012) Filler injections with the blunt-tip microcannula Compared to the sharp hypodermic needle.

21. DeJoseph LM (2012) Cannulas for facial filler placement. Facial Plast Surg Clin North Am 20(2): 215-220.

22. Zeichner JA, Cohen JL (2012) Use of blunt tipped cannulas for soft tissue fillers. J Drugs Dermatol 11(1): 70-72. 
(C) This work is licensed under Creative Commons Attribution 4.0 License DOI: 10.19080/JOJDC.2018.01.555554

\section{Your next submission with Juniper Publishers will reach you the below assets}

- Quality Editorial service

- Swift Peer Review

- Reprints availability

- E-prints Service

- Manuscript Podcast for convenient understanding

- Global attainment for your research

- Manuscript accessibility in different formats ( Pdf, E-pub, Full Text, Audio)

- Unceasing customer service

Track the below URL for one-step submission https://juniperpublishers.com/online-submission.php 